Preprints of the

Max Planck Institute for

Research on Collective Goods

Bonn 2012/9

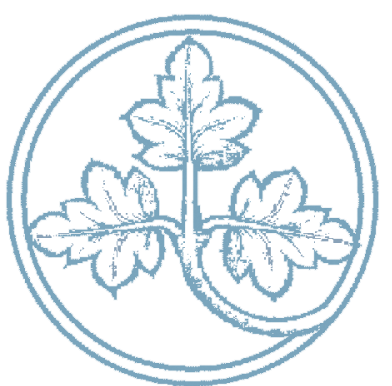

Non-Renewable but

Inexhaustible - Resources in an Endogenous Growth Model

Martin Stürmer

Gregor Schwerhoff

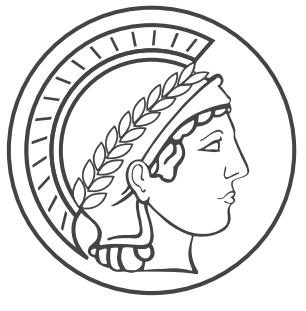




\title{
Non-Renewable but Inexhaustible - Resources in an Endogenous Growth Model
}

\author{
Martin Stürmer / Gregor Schwerhoff
}

April 2012 


\title{
Non-Renewable but Inexhaustible - Resources in an Endogenous Growth Model
}

\author{
Martin Stürmer * \\ Gregor Schwerhoff ${ }^{\dagger \ddagger}$
}

April 21, 2012

\begin{abstract}
This paper proposes an endogenous growth model with an essential non-renewable resource, where economic growth enables firms to invest in innovation in the extraction technology and to allocate more capital to resource extraction. Innovation in the extraction technology offsets the deterioration of ore qualities and keeps the production costs of the non-renewable resource constant. Aggregate output as well as production and use of the non-renewable resource increase exponentially. Our model explains the long-run trends of non-renewable resource prices and world production over more than 200 years. If historical trends in technological progress and in the deterioration of ore qualities continue, it is in the realm of possibility that non-renewable resources are de facto inexhaustible. Our results suggest that the industrialization in China and other emerging economies contributes to keeping non-renewable resource prices constant in the long run.
\end{abstract}

JEL classification: O44, Q32, Q33

Keywords: Non-Renewable Resources, Endogenous Growth, Extraction Technology

*Institute for International Economic Policy (IIW), University of Bonn: Lennéstraße 37, 53113 Bonn, Germany. Email: martin.stuermer@uni-bonn.de

${ }^{\dagger}$ Bonn Graduate School of Economics (BGSE): Adenauerallee 24, 53113 Bonn, Germany and Max Planck Institute for Research on Collective Goods: Kurt-Schumacher-Str. 10, 53113 Bonn, Germany. Email: gschwerh@uni-bonn.de

¥ We thank Martin Hellwig, Jürgen von Hagen, Dirk Krüger, Lars Kunze, Friedrich-Wilhelm Wellmer, Florian Neukirchen, Sandro Schmidt and Gert Pönitzsch for useful discussion and comments. All remaining errors are ours. 


\section{Introduction}

Our model contributes to resolving a contradiction between theoretical predictions and empirical evidence on non-renewable resources. According to growth theory, economic growth is not necessarily limited by non-renewable resources due to three factors: technical change, substitution of non-renewable resources by capital, and returns to scale. Given these factors, growth models with a non-renewable resource typically predict growth in output:1 decreasing non-renewable resource extraction, and an increasing resource price (see Groth, 2007; Aghion and Howitt, 1998).

However, it is a well-established fact that these predictions are not in line with the empirical evidence from the historical evolution of prices and production of non-renewable resources. Real prices have either been roughly trendless over time or stationary around deterministic trends with infrequent structural breaks, whereas the extraction of non-renewable resources has strongly increased (see Krautkraemer, 1998; Livernois, 2009; Cynthia-Lin and Wagner, 2007).

We add an essential, non-renewable resource and innovation in the extraction technology to the endogenous growth model of Aghion and Howitt (1998). The extractable quantity of the non-renewable resource is a function of extraction costs. In the optimal solution, exponential economic growth triggers exponentially growing investment in the extraction technology. This offsets the cost-increasing effects of extracting the non-renewable resource from occurrences with lower ore grades, where "ore grade" is the concentration of a resource in the earth's crust. Hence, the extraction and use of the non-renewable resource increase exponentially, whereas its production costs stay constant over the long run. We provide evidence from data on prices and primary production of major non-renewable resources in the past 200 years. Our results suggest that the industrialization of China and other emerging economies might trigger investment in cost-reducing extraction technologies. If historical trends continue, innovation in the extraction technology will offset the depletion of easily accessible deposits. Even if non-renewable resource use and production increase exponentially, resource prices might stay constant in the long run.

Earlier papers take technological innovation in the extraction technology as given and do not include output growth. Heal (1976) introduced a non-renewable resource, which is

\footnotetext{
${ }^{1}$ As Grimaud and Rougé (2003) point out, optimal output growth may be negative in a growth model with non-renewable resources, even when positive or no growth is possible.
} 
inexhaustible, but available at different grades and costs in a classical Hotelling (1931) optimal depletion model. Extraction costs increase with cumulative extraction, but then remain constant as a "backstop" supply is reached. Slade (1982) added exogenous technological progress in the extraction technology to the Hotelling (1931) model and predictes a U-shaped relative price curve. Cynthia-Lin and Wagner (2007) use a similar model with an inexhaustible non-renewable resource and obtain a constant relative price and increasing extraction.

There are two papers, to our knowledge, that are close to ours in that they include technological progress in the extraction of a non-renewable resource in an endogenous growth model. Fourgeaud et al. (1982) focus on explaining sudden fluctuations in the development of non-renewable resource prices. Tahvonen and Salo (2001) model the transition from a nonrenewable energy resource to a renewable energy resource. Their model follows a learningby-doing approach as technical progress is linearly related to the level of extraction and the level of productive capital. It explains decreasing prices and increasing consumption of a non-renewable energy resource for a certain time period.

In comparrison to the existing literature, our model combines technological progress in the extraction technology and the deterioration of the resource stock in an endogenous growth model that explicitly models the investment in the innovation of the extraction technology. Our model is clearly a strong simplification. To focus on the main argument, we abstract from externalities, uncertainty, recycling, substitution, short run price fluctuations, and exploration in the following. Like the aforementioned literature, we derive a social planner solution to make our point. Hence, we make no policy recommendations. A decentralised solution could shed light on the effect of externalities and the effects of a resource tax as well as other policies on the growth of the economy.

In Section 2, we document stylized facts on the long-run development of non-renewable resource prices, production, and output. We also provide geological evidence for major assumptions of our model. Section 3 presents the model and its theoretical results. Section 4 concludes. 


\section{Stylized Facts}

\subsection{Prices, Production, and Output in den Long Run}

Annual data for major non-renewable resource markets from 1792 to 2010 indicates that real prices are roughly trendless and world primary production and world output grow exponentially.

\section{Insert figure 1 about here.}

Figure 1 presents data on the real prices of five major base metals and crude oil. Real prices exhibit strong short-term fluctuations. At the same time, the growth rates of all prices are not significantly different from zero (see Table 1). The real prices are hence trendless. This is in line with evidence over shorter time periods provided by Krautkraemer (1998); Cynthia-Lin and Wagner (2007) and references therein. The real price for crude oil exhibits structural breaks, as Dvir and Rogoff (2009) point out. Overall, the literature is certainly not conclusive (see Pindyck, 1999, Lee et al., 2006; Slade, 1982), but we believe the evidence is sufficient to take trendless long-term prices as a motivation for our model.

\section{Insert figure 2 about here.}

Figure 2 shows that the world primary production of the examined non-renewable resources and world GDP approximately exhibit exponential growth since 1792. A closer statistical examination reveals that the production of the non-renewable resources exhibits significantly positive growth rates in the long run (see Table 2). 1 The growth rates of the production of copper, lead, tin, and zinc do not exhibit a statistically significant trend over the long run. Hence, the levels of production of these non-renewable resources grow exponentially over time.

\section{Insert tables 1 to 3 about here.}

\footnotetext{
${ }^{1}$ The following results are quite robust for per capita values of the dataset, as table 3 shows.
} 
The level of crude oil production follows this exponential pattern only until 1975. Including the time period from 1975 until 2009 reveals a statistically significant negative trend and therefore diminishing growth rates over time, due to a structural break in the oil market (Dvir and Rogoff, 2009, Hamilton, 2009). In the case of aluminum, we also find diminishing growth rates over time and hence no exponential growth of the production level. This might be due to the fact that recycling has become important in aluminum production. Recycling is neither included in our model nor in the data. The growth rates of world GDP exhibit an increasing trend over the long run, hinting at an underlying explosive growth process.

As our model does not include population growth, we run the same tests for the per capita data of the respective time series and find slightly weaker results as table 3 shows. There is strong evidence that the growth rates of the production of copper and zinc are positive and mostly trendless in the long run. Hence, their levels of production grow exponentially over time. We find the same result for tin only for the the very long time period from 1792 to 2009 , but not for subperiods. Growth rates of lead production exhibit a statistically significant negative trend for long time periods and no statistically significant constant trend for the shorter time periods. The results for per capita aluminum and crude oil production as well as per capita GDP do not significantly change compared to the data in absolute values.

\subsection{Innovation and Extraction Technology}

Minerals are available at different extraction costs in the earth's crust. Several reasons account for this phenomenon, including varying ore grades, thickness, and depths of occurrences.

The definition of resources by the US-Geological Survey reflects this fact. It defines resources as "a concentration of naturally occurring solid, liquid, or gaseous material in or on the earth's crust in such form and amount that economic extraction (...) from the concentration is currently or potentially feasible." (U.S. Geological Survey, 2011b, p. 193). The term "economic" implies that profitable extraction under defined investment assumptions has been established. (...) The boundary between resources and other occurrences "is obviously uncertain, but limits may be specified in terms of grade, quality, thickness, depth, percent extractable, or other economic-feasibility variables." (U.S. Geological Survey, 2011b, p. 194).

Over time, innovation in extraction technology, namely in prospection, mining, and metallurgy, has made it profitable to extract minerals from occurrences with lower ore grades or of greater depths (see Wellmer, 2008). The example of copper in figure 3 in the appendix 
illustrates that the ore grades of U.S. copper mines have constantly decreased over the long run. Radetzki (2009) describes how technological innovation has made the extraction of copper from ever-decreasing ore grades possible. 7000 years ago, human beings used copper from a pure nugget form (100\% ore grade). Small investments in innovation of extraction technologies and metallurgyn has gradually made extraction from deposits of lower ore grade possible. Today, humanity extracts copper from deposits of $0.2 \%$ ore grade.

\section{Insert figure 3 about here.}

The historical development suggests that the cost of innovation might increase exponentially in making an additional ore grade accessible. Decreasing the extractable ore grade from $50 \%$ to $49 \%$ has probably required only a small investment, but decreasing it from $1.2 \%$ to $0.2 \%$ required a lot of investment into technological progress.

The amount of resources for which extraction is considered economically feasible is called reserves. It has stayed constant or even increased in the past decades for most non-renewable resources as a consequence of innovation in the extraction technology. Figure 4 shows that the reserves of copper have increased by more than 600 percent over the last 60 years. One reason is the introduction of the solvent extraction electrowinning technology. This two stage process has made the extraction of low grade copper ores economically feasible (Bartos, 2002). Case studies for other minerals also find that innovation in the extraction technology has offset cost increasing degradation of resources (see for example Lasserre and Ouellette, 1988).

\section{Insert figures 4 to 5 about here.}

We observe similar developments in the case of hydrocarbons. Using the example of the offshore oil industry, Managi et al. (2004) show that innovation in the extraction technology has offset cost-increasing degradation of resources. Crude oil has been extracted from ever deeper sources in the Gulf of Mexico. Furthermore, technological innovation and high prices have made it profitably to extract liquid hydrocarbons not only from sedimentary basins, but also from oil shales. As a consequence, oil reserves have doubled since the 1980s (see figure 5). Moreover, liquid fuels are increasingly produced from gas shales and coal. Bartis et al. (2008) estimate the costs of producing liquid fuels from coal to be 55 to 65 US-Dollar per barrel crude oil equivalent. 


\subsection{Geological Distribution in the Earth's Crust}

Computing the total abundance of each of the elements in the earth's crust leads to enormous quantities (see Nordhaus, 1974). Table 4 shows that this includes even such minerals as gold, which are commonly thought to be the most scarce. Hydrocarbons are quite common in the sediments of the earth's crust as well. Even though conventional oil resources are certainly limited, non-conventional oil resources, natural gas, and coal are abundant. Overall, Rogner (1997) assesses world hydrocarbon resources and concludes that "fossil energy appears almost unlimited" (p. 249) given a continuation of historical technological trends.

\section{Insert table 4 about here.}

The quantity of minerals is not uniformly distributed across the different ore grades in the earth's crust. Geochemical processes have decreased or increased the local abundance during history. Unfortunately, geologists do not agree on the distribution of the elements in the earth's crust. Ahrens (1953, 1954) states in his fundamental law of geochemistry that the elements in the earth's crust exhibit a lognormal concentration value distribution. Skinner (1979), Gordon et al. (2007), and others propose a discontinuity in this distribution due to the so-called "mineralogical barrier", the approximate point below which metal atoms are trapped by atomic substitution. Due to a lack of geological data, both parties acknowledge that an empirical proof is still outstanding. In a recent empirical study, Gerst (2008) concludes that he can neither confirm nor refute these two hypotheses. Based on worldwide data on copper deposits over the past 200 years, he finds evidence for a lognormal relationship between copper production and average ore grades. With respect to inference about future supply, we acknowledge that there is uncertainty about the extent of non-linearities in the distribution of the elements in the earth's crust. This is especially tre for hydrocarbons, which might significantly differ due to the distinct formation processes. For example, oil begins to form in the source rock due to the thermogenic breakdown of organic matter (cerogen) at about 60-120 degrees Celsius, which is found in approximately 2-4km if depth. 


\section{The Model}

We set up a model of endogenous growth with a non-renewable resource, where we assume that the stock of the resource is only limited at a given cost and for a given technology. By investing in the extraction technology, the available stock for a given technology cost expands. The growth model is a social planner approach.

\subsection{The Extraction Cost Function}

We model two different types of cost for extracting a non-renewable resource. One is the extraction cost and the other is the cost for investing in innovation of the extraction technology. Let $M_{t}$ be the cumulative amount of capital invested by the social planner in innovation of the extraction technology up to time $t$. We drop the time index to simplify notation. We define the extraction cost function as a function mapping ore grades into extraction costs depending on the state of technology $M$ :

$$
\phi_{M}:[0,1] \times \mathbb{R}_{+} \rightarrow \overline{\mathbb{R}}_{+},(g, M) \mapsto \phi_{M}(g)
$$

For a cumulative investment $M \in \mathbb{R}_{+}$, the social planner extracts the non-renewable resource from deposits of ore grade $g \in[0,1]$ at cost $\phi_{M}(g) \in \overline{\mathbb{R}}_{+}=\mathbb{R}_{+} \cup \infty$. The investment cost for innovation in the extraction technology increases as the ore grade decreases. This implies that $\phi_{M}$ is non-increasing in $g$ :

$$
\forall M: \quad g>g^{\prime} \quad \Rightarrow \quad \phi_{M}(g) \leq \phi_{M}\left(g^{\prime}\right)
$$

We assume that investing in $M$ increases productivity for all ore grades. Therefore, an increase in $M$ decreases extraction costs for any given ore grade:

$$
\forall g: \quad \frac{\partial \phi_{M}(g)}{\partial M} \leq 0
$$

At time $t$, the social planner invests an amount $\frac{\partial M_{t}}{\partial t}$ in innovation of the extractive technology to reduce extraction costs. The social planner determines the investment as an optimization between extraction costs and investment in extraction technology. To simplify this optimization problem, we assume a simple functional form for the technology function. 
Figure 6 panel (a) shows the extraction cost function in its general form. The exploitation of lower ore grades generates higher costs, but with increasing investment in the extraction technology the function moves downward.

\section{Insert figure 6 about here.}

Figure 6 panel (b) illustrates a simple form of the extraction cost function, which we use in the following. In case (b), there is a certain ore grade associated with a unique level of investment in the extraction technology $h_{M}$, above which the social planner can extract the resource at cost $E$. This function $h_{M}$ maps the values of total past technology investments into a value for the ore grade, which is extractable at cost $E$ :

$$
h: \mathbb{R}_{+} \rightarrow[0,1], M \mapsto h_{M} .
$$

At ore grades lower than $h_{M}$, extraction is impossible because the cost is infinite. The technology function takes the degenerate form of

$$
\phi_{M}(g)= \begin{cases}E, & \text { if } \quad g \geq h_{M} \\ \infty, & \text { if } \quad g<h_{M}\end{cases}
$$

This simplifies the optimization. If unextracted deposits with an ore grade larger than $h_{M}$ exist, the social planner extracts them without any investment in innovation of the extraction technology. Otherwise, the social planner needs to invest in innovation to produce the non-renewable resource.

\subsection{The Innovation Cost Function}

The social planner faces a cost of $E$ for extracting a unit of the non-renewable resource. However, to obtain the total production costs of the resource, we have to add the investment in innovation of the extraction technology. To calculate the cost of investing in innovation per unit of the extracted resource, we need to combine two functions.

The first of these functions is $h_{M}$, the cost in terms of $M$ of innovation in the technology 
to extract from deposits of lower ore grade. We consider a functional form of

$$
h_{M}=\gamma_{1} e^{-\gamma_{2} M}
$$

with parameters $\gamma_{1}, \gamma_{2} \in \mathbb{R}_{+}$. Figure 7 panel (a) illustrates the shape of $h_{M}$. The marginal effect of one unit of investment in extraction technology on the extraction of the resource in the ground decreases with diminushing ore grades. This picks up the assumption of section 2.2 that it probably took less investment in extraction technology to change the extractable ore grade from 50 to $49 \%$ than from 2 to $1 \%$.

\section{Insert figure 7 about here.}

The second function is the distribution of the non-renewable resource in the earth's crust. It maps a certain ore grade into the available amount of the resource at that specific ore grade.

$$
D:[0,1] \rightarrow \mathbb{R}_{+}, g \mapsto D(g)
$$

Figure 7 panel (b) illustrates the relationship between the two variables. The total amount of the non-renewable resource is inversely proportional to the ore grade: As the ore grade decreases, the extractable amount of the non-renewable resource increases. This is illustrated by the solid line. For very low ore grades the relationship breaks down as the dashed line on the left shows.

We formulate the relationship in a general way with parameters $\delta_{1}, \delta_{2} \in \mathbb{R}_{+}$and $\delta_{2} \leq 1$ :

$$
D(g)=-\delta_{1} \ln \left(\delta_{2} g\right)
$$

We combine the two function and obtain:

Proposition 1 The marginal cost for one unit of a resource in terms of investment in technology is constant and given by

$$
F=\frac{1}{\delta_{1} \gamma_{2}}
$$

The innovation cost per unit of the resource is constant and independent of the amount $M$ invested in technology previously. It depends on parameters $\gamma_{2}$ and $\delta_{1}$, which determine 
the curvatures of functions (6) and (8). The result depends on the functional forms. As long as the functional forms are both exponential, the marginal innovation cost is a constant.

\subsection{The Production Cost of the Resource}

The social planner has to pay two types of costs to produce a unit of the non-renewable resource. The first is the extraction cost $E$. The second is the innovation cost $F$. We denote both in units of capital.

The stock of the non-renewable resource at time $t$, for which the extraction technology is available, is noted $X_{t} \in \mathbb{R}_{+}$. It is affected by an outflow as in traditional models based on Hotelling (1931) as well as by an inflow. The amount of the extracted resource in period $t$ is $R_{t}$ and the amount of the resource added to the available stock by innovation in the extraction technology is $S_{t}$. Noting time derivatives with a dot over the variable, the evolution of the stock can be written as follows:

$$
\dot{X}_{t}=S_{t}-R_{t}
$$

We bound quantities of innovation and extraction as well as the stock of available resources to be non-negative:

$$
X_{t} \geq 0, S_{t} \geq 0, R_{t} \geq 0
$$

Proposition 1 states that the amount of the resource made available for a given unit of investment in innovation is constant. Following the assumption in equation (5), the extraction cost is constant as well. The total expenditure for the production of the resource at time $t$ is:

$$
R_{t} \cdot E+S_{t} \cdot F
$$

The success of innovation is highly unpredictable. In a world with uncertainty, it is therefore desirable for the social planner to keep a positive amount of the resource $X_{t}$ in order to avoid running out of the resource. In order to focus on long-term developments, however, we abstract from a stochastic innovation process. This implies that the social planner extracts from the original resource stock $X_{0}$ without investment in innovation. From the point where the stock is about to run out, investment starts at the optimal level. The mechanism in the case of stochastic innovation would be very similar with a positive stock used to buffer bad research draws. 


\subsection{The Growth Framework}

We include equations (9) and (11) in a standard Schumpeterian growth model following Aghion and Howitt (1998).

The lifetime utility function of households is

$$
W=\int_{0}^{\infty} e^{-\rho t} u(C) d t
$$

with $\rho>0$ and the isoelastic utility function for consumption $C$,

$$
u(C)=\frac{C^{1-\varepsilon}-1}{1-\varepsilon}, \quad \varepsilon>0 .
$$

The production function for final output is

$$
Y=L^{\beta} \int_{0}^{1} B(i) x(i)^{\alpha} d i R^{\nu}
$$

where $L$ is labor, $B(i)$ is a quality parameter indicating the productivity of intermediate good $i$, and $R$ is the resource as before. Intermediate good producers produce according to the constant-returns production function $x(i)=K(i) / B(i)$, where $K(i)$ is the amount of capital used to produce $i$. It is optimal to produce the same quantity of each intermediate good $x(i)=K / B$. This simplifies the production function to

$$
Y=K^{\alpha} B^{1-\alpha} L^{\beta} R^{\nu}
$$

The coefficients $\alpha, \beta, \nu$ are all positive with

$$
\alpha+\beta+\nu=1
$$

Thus, for a given state of innovation there are constant returns to scale in the three inputs capital, labor and the non-renewable resource.

Note that the model includes two types of technology: The extraction technology and the general production technology of the intermediate good producers as in the standard Schumpeterian model.

There is a total supply of labor normalized to 1 . This is distributed to research in the 
general production technology, noted $n$, and manufacturing $L$, so that

$$
L=1-n
$$

This allocation will be endogenously determined.

The evolution of the general production technology is given as

$$
\dot{B}=\sigma \eta n B
$$

$\sigma$ is a parameter representing the size of each innovation. $\eta$ is a parameter of the research technology indicating the Poisson arrival rate of innovations to a single research worker. The details of the setup up to this point are as in Aghion and Howitt (1998). We include the production cost for the non-renewable resource (11) in the model.

The change in the capital stock is given as

$$
\dot{K}=Y-C-E R-F S .
$$

The social planner allocates total production to consumption $C$, investment $\dot{K}$, extraction cost $E R$, and investment in innovation of the extraction technology FS.

In our framework, the development of the production technology for intermediate goods is endogenous and depends on the share of labor in the research sector, equation (17). At the same time, the social planner invests capital in innovation of the extraction technology. Unlike the sector for intermediate goods, which could keep on producing without additional research in the production technology, the extractive sector needs investment in innovation for each unit it produces. Hence, there is a trade-off between the different technology investments. If more labor is invested in research for the production technology, less labor is available as an input to the production of output. This reduces capital output, which is needed as an input to innovation in the extraction technology. In equilibrium, the social planner allocates investments in innovation of the production technology and the extraction technology in such a way as to equalize productivity in terms of consumption. 


\subsection{Theoretical Results}

As a first step, we show that the intuition concerning the management of the stock can be verified. In an economy without uncertainty, the social planner does not invest in innovation of the extraction technology, $S$, as long as a positive stock of the extractable resource, $X$, remains.

Proposition 2 As long as a positive stock of the non-renewable resource remains, there is no investment in innovation of the extraction technology:

$$
X>0 \Rightarrow S=0 \text {. }
$$

As soon as the stock of the resource is zero, the new stock of the non-renewable resource, which becomes available through investment in innovation of the extraction technology, is equal to the extraction of the resource:

$$
X=0 \quad \Rightarrow \quad S=R .
$$

This result of permanently zero resource stocks is due to the assumed absence of uncertainty. Inclusion of uncertainty would obtain $S \approx R$ for a positive $X^{*}$.

Solving the model, we find

Proposition 3 There is a steady state, in which the common optimal growth rate of consumption $C$, capital $K$ and output $Y$ is

$$
g_{Y}=\frac{1}{\varepsilon}\left(\eta \sigma \frac{1-\alpha}{1-\alpha-\nu}-\rho\right) .
$$

The optimal growth rate of technology is

$$
g_{B}=(1-\varepsilon)\left(1-\frac{\nu}{1-\alpha}\right) g_{Y}+\eta \sigma-\rho+\frac{\nu \rho}{1-\alpha}
$$

We derive a prediction on the extraction and use of the non-renewable resource:

Proposition 4 The extraction and use of the non-renewable resource grows at the same rate as the output, and the ratio of resource extraction to output is given by

$$
\frac{R}{Y}=\frac{\nu}{E+F}
$$


Note that this result relies on the assumption that the production cost per unit of the nonrenewable resource is constant.

Propositions 3 and 4 allow us to understand, which parameters affect the optimal growth rate of the economy and which affect the level of resource extraction:

Proposition 5 The ratio of resource extracvtion to output $\frac{R}{Y}$ is

(i) positively affected by $\nu$, the elasticity of output with respect to the resource,

(ii) negatively affected by $E$, the extraction cost of the resource and

(iii) positively affected by $\delta_{1}$ and $\gamma_{2}$, the two curvature parameters.

The optimal growth rate of the economy $g_{Y}$ is positively affected by $\nu$, the elasticity of output with respect to resources.

The cost of extraction $E$ decreases resource extraction and use. $\delta_{1}$ and $\gamma_{2}$ increase the cost of innovation in the extraction technology per unit of the resource. Hence the extraction of the resource increases. An increase in $\nu$ means that production relies more heavily on resource extraction. This has two implications. First, a higher share of capital is invested in the extraction of the resource, inducing a higher resource/output ratio. Secondly, it shifts more importance on the resources (recall that $\alpha+\beta+\nu=1$ ). If the increase in $\nu$ is offset by an decrease in $\alpha$, it leaves the growth rate unaffected. If it is offset by an decrease in $\beta$, the share of labor as an input decreases while the share of the non-renewable resource increases. As the extraction of the non-renewable resource increases exponentially, output grows faster.

\subsection{Discussion}

Our model takes a stylized social planner approach, with constraints on the availability of the physical commodities, notably the non-renewable resource, equation (9), labor, equation (16), and capital, equation (18). Hence, there are no market prices and only production costs. However, a model including a decentralized resource sector would probably yield similar implications for the development of the price. Individual firms would sell the nonrenewable resource at the extraction cost $E+F$ times a mark-up $\mu$. The mark-up would depend on the competition in the sector. The implications of our model would remain the same as long as the mark-up has no long-term trend. A close examination of this aspect is left to future research.

Function $g$ from equation (4) maps the cumulative amount of investment in innovation of the extraction technology into the extractable ore grade. Geologists cannot give an exact 
functional form for $g$, so we used the form given in (6) as a plausible hypothesis. How would other functional forms affect the predictions of the model? First, the predictions are valid for all parameter values $\gamma_{1}, \gamma_{2} \in \mathbb{R}_{+}$. Secondly, if $g$ is discontinuous with a break at $M_{0}$, at which parameters change to $\gamma_{1}^{\prime}, \gamma_{2}^{\prime} \in \mathbb{R}_{+}$, there would be two balanced growth paths: one for the period before and one for the period after the break. Both would behave according to the predictions of the model. They would differ in the capital cost of producing the resource and the extraction and use of the resource in the economy. To see this, recall from Proposition 1 that $F$ is a function of $\gamma_{2}$. A non-exponential form of $g$ would produce results that differ from ours, such as a positive trend in resource prices. If at some ore grade extraction becomes infeasible, the planner would have to consider the opportunity cost of extracting the resource in the future in addition to extraction and innovation cost. In this case, the model would become similar to the one in Aghion and Howitt (1998).

How does this model compare to a model with finite resources? Unlike many models with non-renewable resources, we do not assume that resources are finite, as their availability is a function of technological progress. As a consequence, resource availability does not limit growth. Substitution of non-renewable resources by capital, technological progress in the use of the resource and increasing returns to scale are therefore not necessary for sustained growth. Growth depends on technological progress as much as it does in standard growth models without a non-renewable resource.

Our model suggests that the non-renewable resource can be thought of as a form of capital: The social planner has to invest into the resource, but if he does invest, it is available without limits as an input to production. This feature marks a distinctive difference to models such as that of Bretschger and Smulders (2003). They investigate the effect of various assumptions on substitutability and a decentralized market on long-run growth, but keep the assumption of finite resources. Without this assumption, the elasticity of substitution between the nonrenewable resource and other input factors is not central to the analysis of limits to growth anymore.

Our model with finite resources is given in Aghion and Howitt (1998). In their model, the finite stock of the resource gradually declines. Over time, production and use of the non-renewable resource decrease while prices increase. The optimal growth rate of the model is given by

$$
g_{Y}=\frac{1}{\varepsilon}(\eta \sigma-\rho)
$$


This is similar to our model, but our model exhibits an additional $\nu$, the elasticity of output with respect to the resource, entering negatively into the denominator. The optimal growth rate in our model is higher, as growth is not constrained by a finite non-renewable resource and as two of the three inputs, capital and the resource, grow exponentially.

How robust are our results to changes in the production function? The Cobb-Douglas production function is the standard assumption in Schumpeterian models and endogenous growth models, see Aghion and Howitt (1998), Barro and Sala-i-Martin (2004), and Acemoglu (2009). It is a special case of an elasticity of substitution of 1 . As Dasgupta and Heal (1979) point out, the question of limits to growth depends crucially on substitutability. Following these authors, we generalize our production function to a CES production function:

$$
Y=B\left[\alpha K^{\frac{\psi-1}{\psi}}+\beta L^{\frac{\psi-1}{\psi}}+\nu R^{\frac{\psi-1}{\psi}}\right]^{\frac{\psi}{\psi-1}}
$$

In the case of $\psi>1$, the resource is not necessary for production of output. $\psi=1$ is the case of the Cobb-Douglas production function. In the remaining case, $\psi<1$, total output is strictly less than total resources available multiplied by a constant. If the resource is finite, output has to decline to zero. In our model, the non-renewable resource is not finite, so that there is no upper bound for output.

\section{Conclusion}

This paper examines the long run evolution of prices and production of major non-renewable resources from a theoretical and empirical perspective. We argue that economic growth causes the production and use of a non-renewable resource to increase exponentially and its production costs to stay constant in the long run. Economic growth enables firms to invest into innovation of the extraction technology and to allocate more capital to resource extraction. We explain the long run evolution of non-renewable resource prices and world production over more than 200 years. If historical trends of technological progress continue, it is in the realm of possibility that non-renewable resources are de facto inexhaustible in a time frame relevant to human civilization.

Our model does not include recycling, which will probably become more important for minerals in the future due to an increasing stock of recycleable materials and the comparatively low energy requirements (see Steinbach and Wellmer, 2010). Introducing recycling in 
our model would probablyn further strengthen our argument.

Our results are a positive statement on past developments and future possibilities. They do not make a normative statement on how these possibilities should be used. Resource extraction and the use of non-renewable resources is associated to negative environmental externalities. Internalizing these externalities is a field of analysis in itself (see Acemoglu et al. 2012).

We leave a decentralised solution of our model to study effects of policies such as a resource tax on innovation and output growth to future research. 


\section{References}

Acemoglu, D. (2009). Introduction to Modern Economic Growth. Princeton University Press.

Acemoglu, D., Aghion, P., Bursztyn, L., and Hemous, D. (2012). The environment and directed technical change. American Economic Review, 102(1):131-66.

Aghion, P. and Howitt, P. (1998). Endogenous Growth Theory. MIT Press.

Ahrens, L. (1953). A fundamental law of geochemistry. Nature, 172:1148.

Ahrens, L. (1954). The lognormal distribution of the elements (a fundamental law of geochemistry and its subsidiary). Geochimica et Cosmochimica Acta, 5(2):49-73.

Barro, R. and Sala-i-Martin, X. (2004). Economic Growth. New York: McGraw Hill.

Bartis, J., Camm, F., and Ortiz, D. (2008). Producing Liquid Fuels from Coal: Prospects and Policy Issues, volume 754. Rand Corp.

Bartos, P. (2002). Sx-ew copper and the technology cycle. Resources Policy, 28(3-4):85-94.

BP plc (2010). BP statistical review of world energy, June 2010.

Bretschger, L. and Smulders, S. (2003). Sustainability and substitution of exhaustible natural resources. How resource prices affect long-term R\&D investments. Mimeo Center Tilburg University.

Cynthia-Lin, C. and Wagner, G. (2007). Steady-state growth in a Hotelling model of resource extraction. Journal of Environmental Economics and Management, 54(1):68-83.

Dasgupta, P. and Heal, G. (1979). Economic theory and exhaustible resources. Cambridge Economic Handbooks (EUA).

Dvir, E. and Rogoff, K. S. (2009). Three epochs of oil. Working Paper 14927, National Bureau of Economic Research.

Federal Institute for Geosciences and Natural Resources (2011a). Reserven, Ressourcen, Verfügbarkeit von Energierohstoffen 2011. Federal Institute for Geosciences and Natural Resources/ German Mineral Resources Agency. 
Federal Institute for Geosciences and Natural Resources (2011b). Price database. Federal Institute for Geosciences and Natural Resources.

Federal Institute for Geosciences and Natural Resources (2011c). Production database. Federal Institute for Geosciences and Natural Resources.

Fourgeaud, C., Lenclud, B., and Michel, P. (1982). Technological renewal of natural resource stocks. Journal of Economic Dynamics and Control, 4(1):1-36.

Gerst, M. (2008). Revisiting the cumulative grade-tonnage relationship for major copper ore types. Economic Geology, 103(3):615.

Gordon, R., Bertram, M., and Graedel, T. (2007). On the sustainability of metal supplies: A response to Tilton and Lagos. Resources Policy, 32(1-2):24-28.

Grimaud, A. and Rougé, L. (2003). Non-renewable resources and growth with vertical innovations: optimum, equilibrium and economic policies. Journal of Environmental Economics and Management, 45(2):433-453.

Groth, C. (2007). A new growth perspective on non-renewable resources. In Bretschger, L. and Smulders, S., editors, Sustainable Resource Use and Economic Dynamics, chapter 7, pages $127-163$. Springer.

Hamilton, J. (2009). Understanding crude oil prices. The Energy Journal, 30(2):179-206.

Heal, G. (1976). The relationship between price and extraction cost for a resource with a backstop technology. The Bell Journal of Economics, 7(2):371-378.

Hotelling, H. (1931). The economics of exhaustible resources. Journal of Political Economy, 39(2):137-175.

Krautkraemer, J. (1998). Nonrenewable resource scarcity. Journal of Economic Literature, $36(4): 2065-2107$.

Lasserre, P. and Ouellette, P. (1988). On measuring and comparing total factor productivities in extractive and non-extractive sectors. Canadian Journal of Economics, 21(4):826-34.

Lee, J., List, J., and Strazicich, M. (2006). Non-renewable resource prices: Deterministic or stochastic trends? Journal of Environmental Economics and Management, 51(3):354-370. 
Littke, R. and Welte, D. H. (1992). Hydrocarbon source rocks. Cambridge University Press.

Livernois, J. (2009). On the empirical significance of the hotelling rule. Review of Environmental Economics and Policy, 3(1):22-41.

Maddison, A. (2010). Historical statistics of the world economy: 1-2008 AD.

Managi, S., Opaluch, J., Jin, D., and Grigalunas, T. (2004). Technological change and depletion in offshore oil and gas. Journal of Environmental Economics and Management, 47(2):388-409.

Metallgesellschaft (1904). Statistische Zusammenstellungen ueber Aluminium, Blei, Kupfer, Zink, Zinn, Kadmium, Magnesium, Nickel, Quecksilber und Silber. Metallgesellschaft AG.

Neumann, B. (1904). Die Metalle. Geschichte, Vorkommen und Gewinnung. W. Knapp.

Nordhaus, W. (1974). Resources as a constraint on growth. American Economic Review, $64(2): 22-26$.

Officer, L. (2011a). The annual consumer price index for the united states, 1774-2010. http://www.measuringworth.com/uscpi/ accessed on 11 April 2012.

Officer, L. (2011b). Dollar-pound exchange rate from 1791. http://www.measuringworth.com/exchangepound/ accessed on 11 April 2012.

Perman, R., Yue, M., McGilvray, J., and Common, M. (2003). Natural resource and environmental economics. Edinburgh (RU). Pearson Education.

Pindyck, R. S. (1999). The long-run evolutions of energy prices. The Energy Journal, 20(2):128.

Radetzki, M. (2009). Seven thousand years in the service of humanity-the history of copper, the red metal. Resources Policy, 34(4):176 - 184.

Rogner, H. (1997). An assessment of world hydrocarbon resources. Annual Review of Energy and the Environment, 22(1):217-262.

Schmitz, C. (1979). World Non-Ferrous Metal Production and Prices. 1700-1976. Routledge Chapman and Hall.

Skinner, B. (1979). A second iron age ahead? Studies in Environmental Science, 3:559-575. 
Slade, M. (1982). Trends in natural-resource commodity prices: An analysis of the time domain. Journal of Environmental Economics and Management, 9(2):122-137.

Steinbach, V. and Wellmer, F. (2010). Consumption and use of non-renewable mineral and energy raw materials from an economic geology point of view. Sustainability, 2(5):14081430.

Tahvonen, O. and Salo, S. (2001). Economic growth and transitions between renewable and nonrenewable energy resources. European Economic Review, 45(8):1379-1398.

Tilton, J. and Lagos, G. (2007). Assessing the long-run availability of copper. Resources Policy, 32(1-2):19-23.

U.S. Bureau of Labor Statistics (2010). Consumer price index. All urban consumers. US city average. All items. ftp://ftp.bls.gov/pub/special.requests/cpi/cpiai.txt accessed on 11 April 2012.

US Bureau of Mines (1980). Minerals yearbook. 1978-79. Metals and minerals. US Bureau of Mines.

U.S. Geological Survey (2010). Gold statistics. U.S. Geological Survey, Reston, Virginia.

U.S. Geological Survey (2011a). 2010 Minerals Yearbook. U.S. Geological Survey, Reston, Virginia.

U.S. Geological Survey (2011b). Mineral Commodity Summaries 2011. U.S. Geological Survey, Reston, Virginia.

U.S. Geological Survey (2012). Mineral Commodity Summaries 2012. U.S. Geological Survey, Reston, Virginia.

Wagner, M. and Wellmer, F. (2009). Global mineral resources, occurrence and distribution. In Hasan, S. and Qureshy, M., editors, Engineering Geology, Environmental Geology and Mineral Economics, Encyclopedia of Life Support Systems. EOLSS Publishers.

Wellmer, F. (2008). Reserves and resources of the geosphere, terms so often misunderstood. Is the life index of reserves of natural resources a guide to the future. Zeitschrift der Deutschen Gesellschaft für Geowissenschaften, 159(4):575-590. 


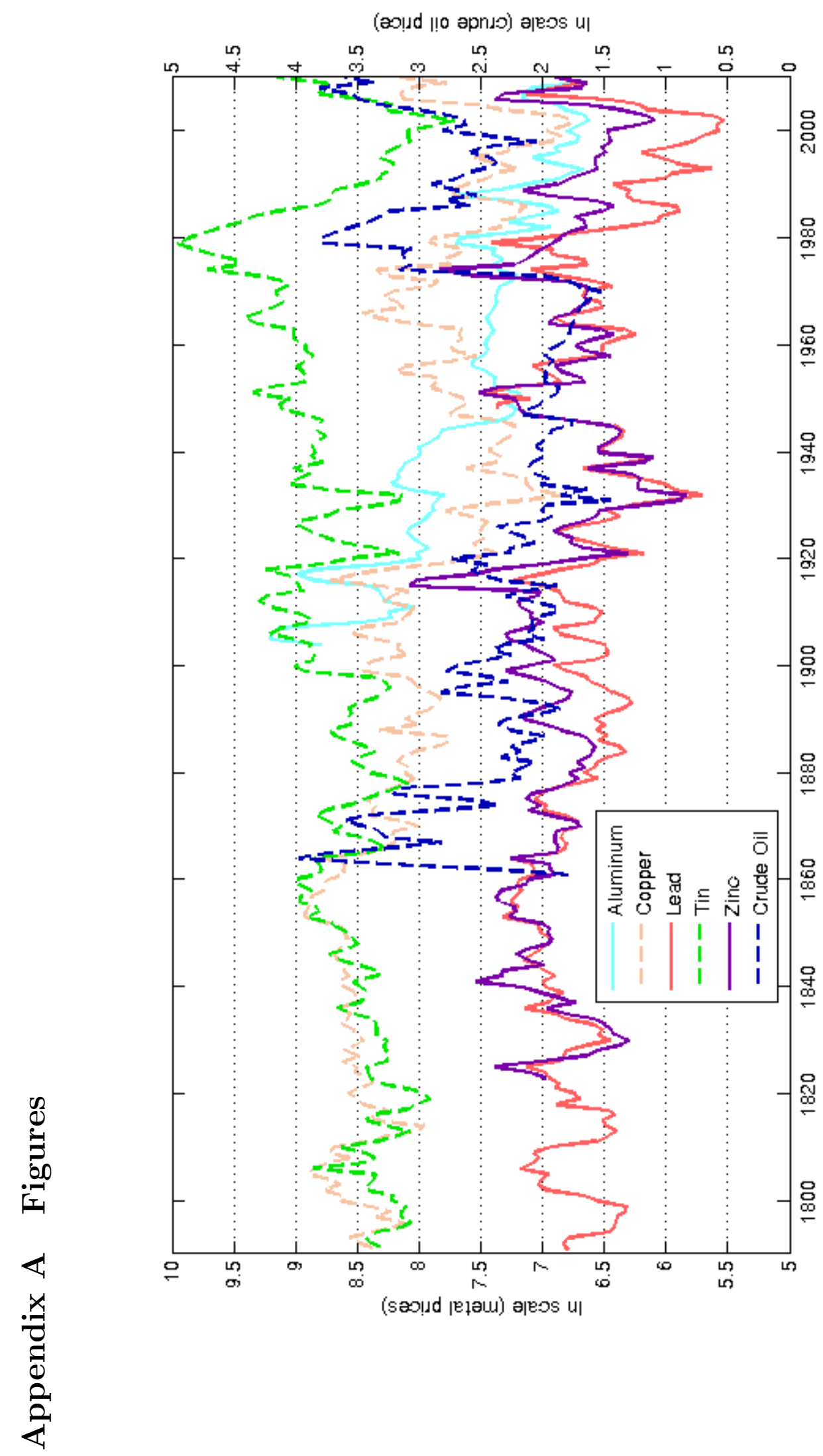

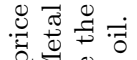

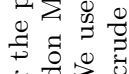

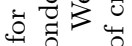

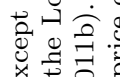

के त्र

记

专要过

iै $\frac{0}{4}$ 过

之.

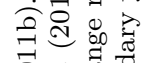

일 $\frac{0}{0}$

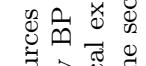

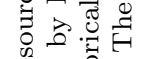

㫕

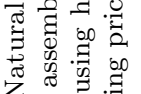

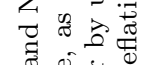

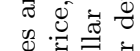

르웅

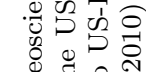

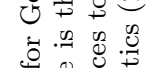

先

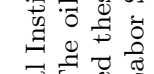

苞

选 000

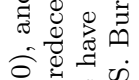

$\begin{array}{llll}0 & 0 & 0 & 0 \\ 0 & 0 & 0 \\ 0 & 0 & 0 & 0 \\ 0 & 0 & 0 & 0\end{array}$

च

政

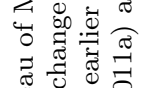

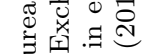

品

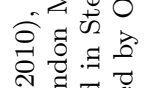

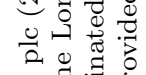

西要

Sil d d

次。

굴

齐

$\ddot{0}$ :

U. 


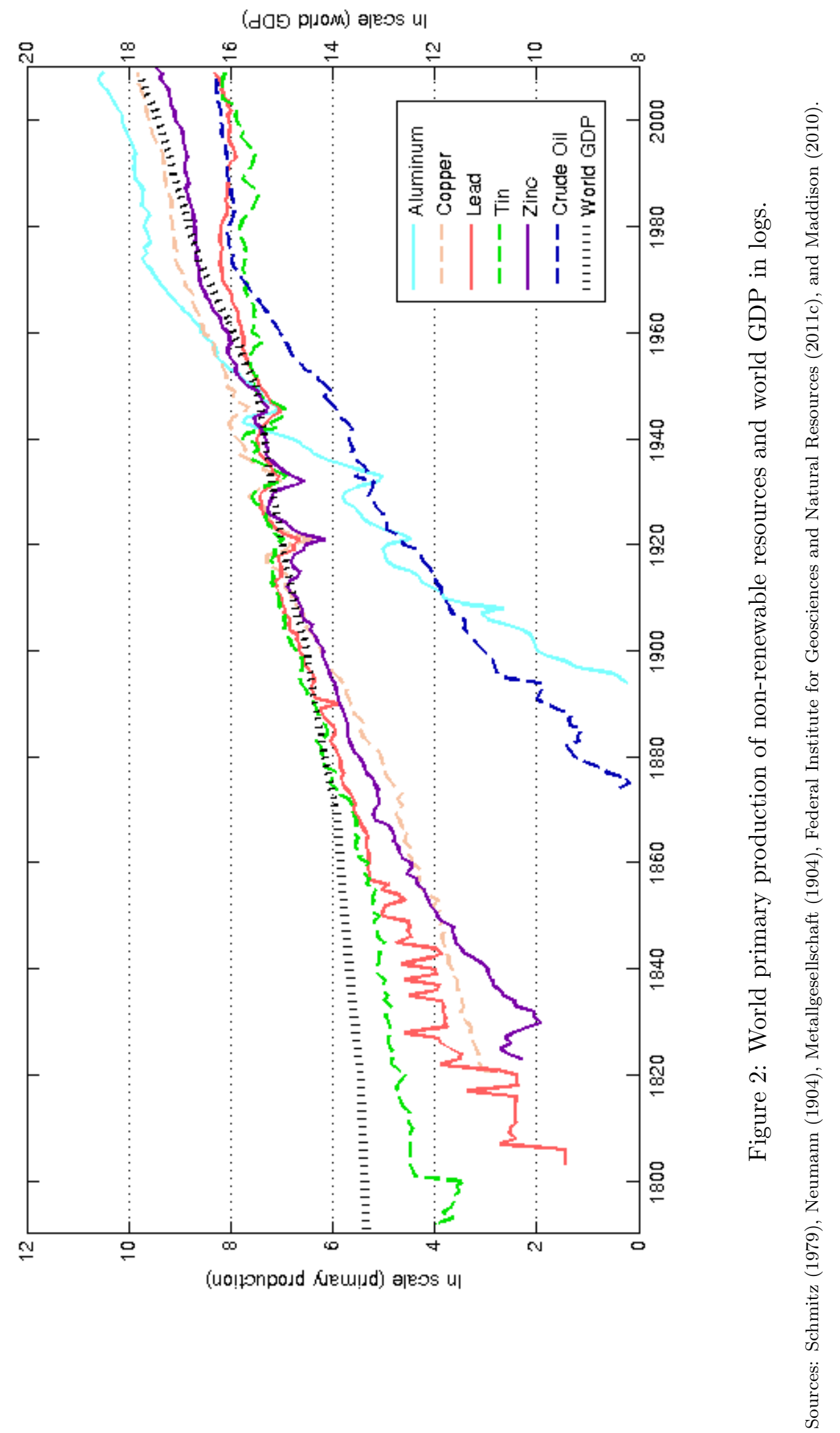




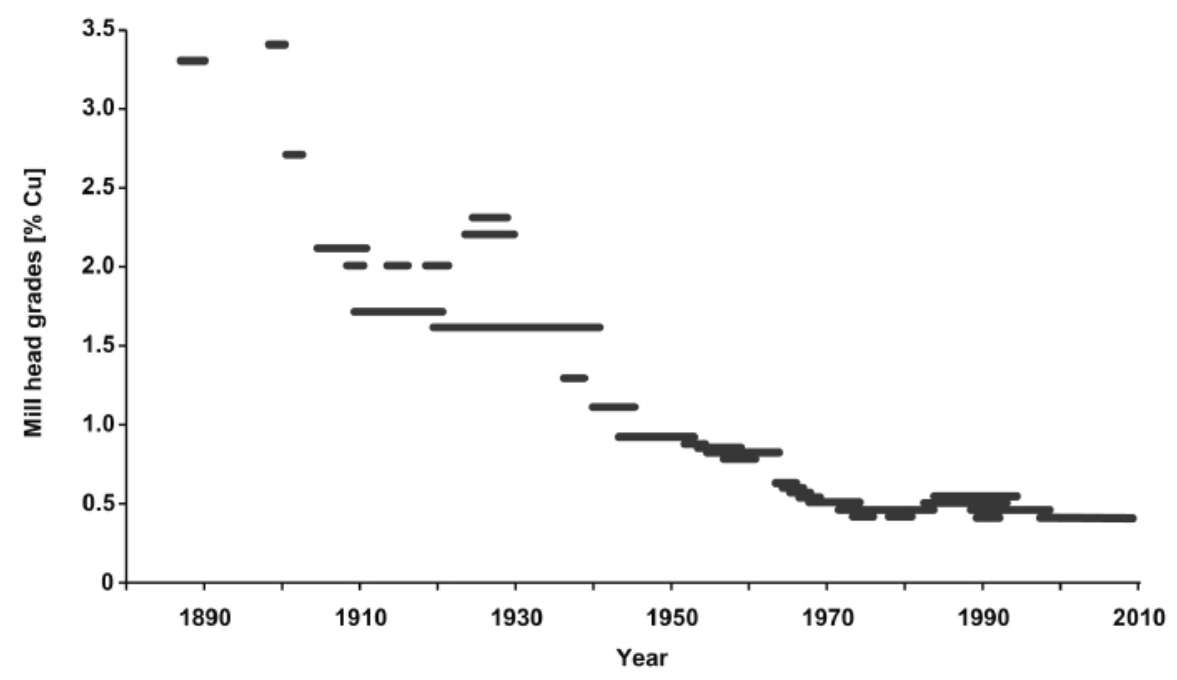

Figure 3: Historical Development of Mining of Various Grades of Copper in the U.S. Source: Wagner and Wellmer (2009).

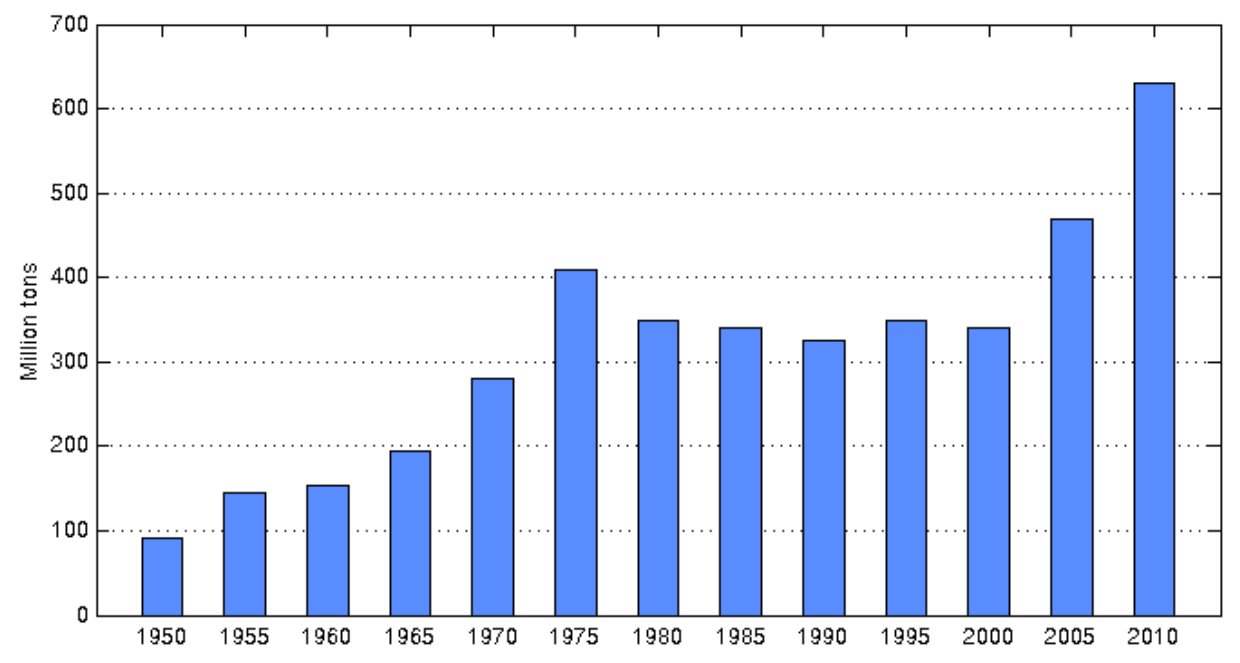

Figure 4: Historical Evolution of World Copper Reserves, 1950 - 2010. Sources: Tilton and Lagos (2007), U.S. Geological Survey 2011b). 


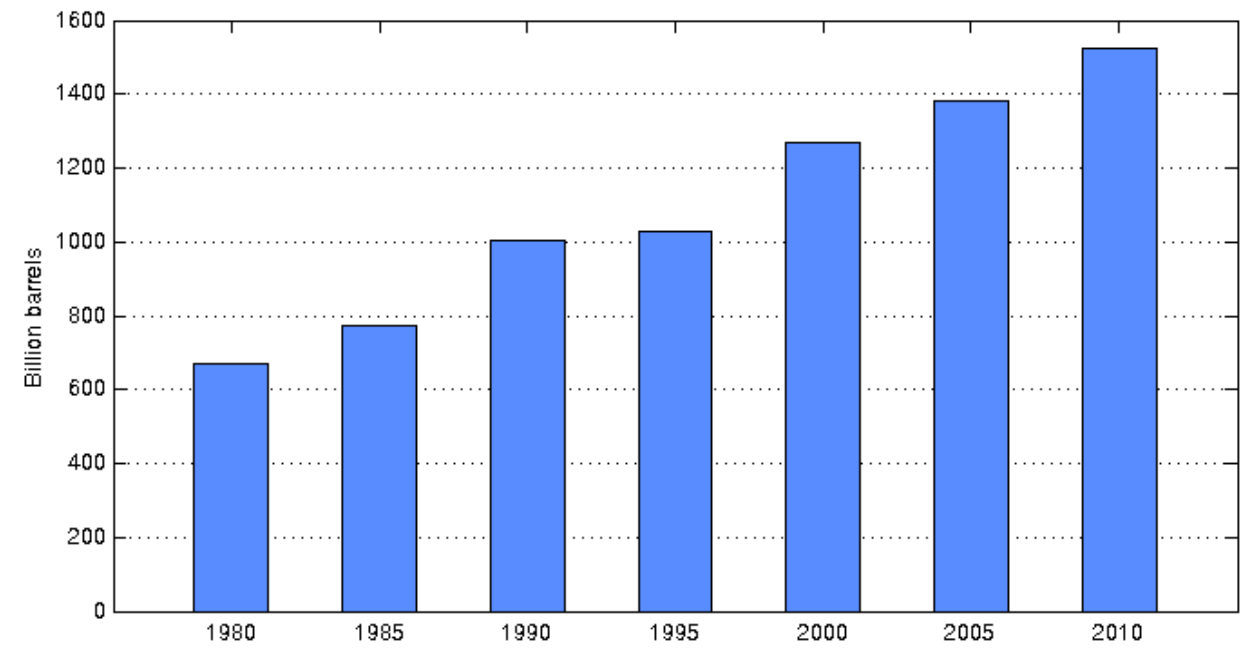

Figure 5: Historical Evolution of Oil Reserves, including Canadian Oil Sands, 1980 - 2010. Source: BP plc (2010).

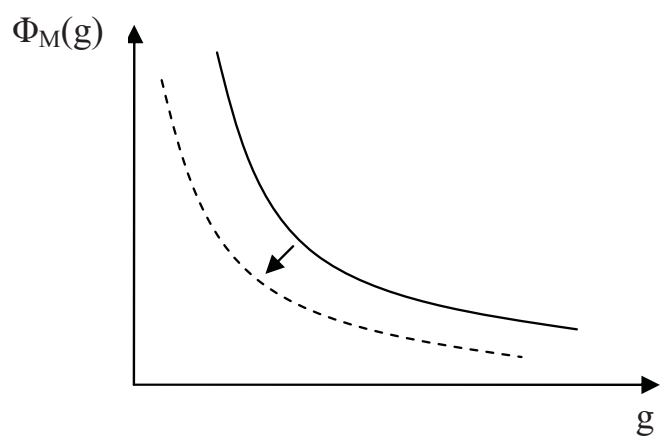

(a)

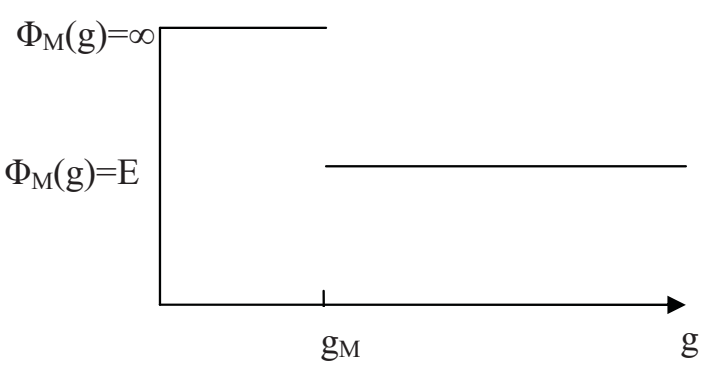

(b)

Figure 6: Extraction Costs as a Function of Ore Grades 


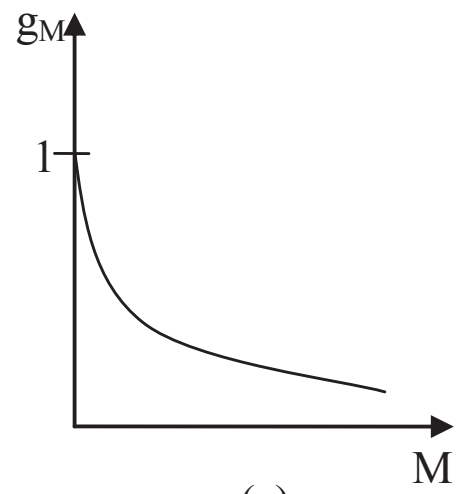

(a)

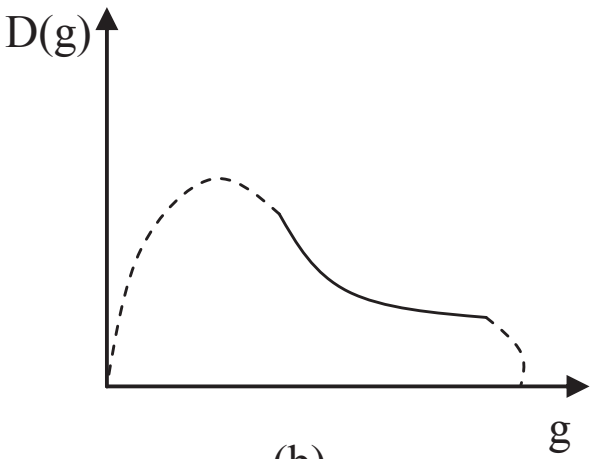

(b)

Figure 7: (a) Extractable ore grade a function of accumulated investment in technology (b) Amount of the non-renewable resource in the earth's crust available at a given grade.

\section{B Tables}

\begin{tabular}{lrrrrrrr}
\hline & & Aluminum & Copper & Lead & Tin & Zinc & Crude Oil \\
\hline Range & & $1905-2009$ & $1792-2009$ & $1792-2009$ & $1792-2009$ & $1824-2009$ & $1862-2009$ \\
Constant & Coeff. & -1.764 & 0.184 & 0.109 & 1.668 & 0.702 & 7.236 \\
& t-stat. & -0.181 & 0.073 & 0.4 & 0.73 & 0.148 & 0.79 \\
Lin.Trend & Coeff. & 0.008 & 0.011 & 0.006 & -0.001 & 0.013 & -0.017 \\
& t-stat. & 0.138 & 0.533 & 0.259 & -0.079 & 0.378 & -0.276 \\
\hline
\end{tabular}

Table 1: Tests of the stylized fact that the growth rates of prices equal zero and do not follow a statistically significant trend. The table presents coefficients and $t$-statistics for regressions of the growth rates on a constant and a linear trend.***, ${ }^{* *}$, and $*$ indicate significance at the $1 \%, 2.5 \%$ and $5 \%$ level, respectively.

Sources: Schmitz (1979), BP plc (2010) and Federal Institute for Geosciences and Natural Resources (2011b). Please see also the note of Figure 1 for further information on the deflation of prices and the exchange rates used. 


\begin{tabular}{|c|c|c|c|c|c|c|c|c|}
\hline & & Aluminum & Copper & Lead & Tin & Zinc & Crude Oil & World GDP \\
\hline Range & & 1855-2009 & 1821-2009 & $1802-2009$ & 1792-2009 & $1821-2009$ & 1861-2009 & $1792-2009$ \\
\hline \multirow[t]{2}{*}{ Constant } & Coeff. & 48.464 & 4.86 & 16.045 & 4.552 & 30.801 & 35.734 & 0.128 \\
\hline & t-stat. & $* * * 3.810$ & $* * * 2.694$ & $* * * 3.275$ & * 2.231 & $* * 2.58$ & $* * * 4.365$ & 0.959 \\
\hline \multirow[t]{2}{*}{ Lin. Trend } & Coeff. & -0.221 & -0.006 & -0.087 & -0.016 & -0.174 & -0.182 & 0.018 \\
\hline & t-stat. & ** -2.568 & -0.439 & ** -2.294 & -0.999 & $*-1.975$ & $* * *-3.334$ & *** 16.583 \\
\hline Range & & $1855-2009$ & 1850-2009 & $1850-2009$ & 1850-2009 & $1850-2009$ & 1861-2009 & 1850-2009 \\
\hline \multirow[t]{2}{*}{ Constant } & Coeff. & 48.464 & 5.801 & 6.032 & 3.569 & 5.579 & 25.198 & 0.995 \\
\hline & t-stat. & *** 3.810 & *** 3.461 & $* * * 3.371$ & * 2.185 & $* * * 3.774$ & $* * * 4.81$ & *** 5.49 \\
\hline \multirow[t]{2}{*}{ Lin.Trend } & Coeff. & -0.221 & -0.018 & -0.038 & -0.015 & -0.021 & -0.182 & 0.019 \\
\hline & t-stat. & ** -2.568 & -1.007 & -1.938 & -0.833 & -1.308 & $* * *-3.334$ & *** 9.797 \\
\hline Range & & 1900-2009 & 1900-2009 & 1900-2009 & 1900-2009 & 1900-2009 & 1900-2009 & 1900-2009 \\
\hline \multirow[t]{2}{*}{ Constant } & Coeff. & 19.703 & 5.965 & 2.980 & 2.844 & 4.44 & 9.883 & 2.004 \\
\hline & t-stat. & $* * * 5.498$ & $* * * 2.651$ & * 2.043 & 1.361 & $* 2.225$ & $* * * 6.912$ & $* * * 7.8$ \\
\hline \multirow[t]{2}{*}{ Trend } & Coeff. & -0.178 & 0.035 & -0.019 & -0.015 & -0.018 & -0.083 & 0.018 \\
\hline & t-stat. & *** 3.174 & -0.995 & -0.853 & -0.464 & -0.592 & $* * *_{-} 3.711$ & $* * * 4.549$ \\
\hline Range & & 1950-2009 & 1950-2009 & 1950-2009 & 1950-2009 & 1950-2009 & 1950-2009 & $1950-2009$ \\
\hline \multirow[t]{2}{*}{ Constant } & Coeff. & 10.781 & 5.043 & 13.205 & 0.051 & 5.675 & 9.897 & 4.729 \\
\hline & t-stat. & *** 7.169 & *** 4.979 & $* * * 2.936$ & 0.028 & *** 4.619 & $* * * 9.574$ & *** 12.89 \\
\hline \multirow[t]{2}{*}{ Lin. Trend } & Coeff. & -0.171 & -0.057 & -0.48 & 0.04 & -0.078 & -0.196 & -0.028 \\
\hline & t-stat. & $* * *-3.999$ & -1.978 & -1.553 & 0.768 & $*-2.255$ & $* * *-6.64$ & $* * *-2.724$ \\
\hline Range & & $1875-1975$ & $1875-1975$ & $1875-1975$ & $1875-1975$ & $1875-1975$ & $1875-1975$ & $1875-1975$ \\
\hline \multirow[t]{2}{*}{ Constant } & Coeff. & 50.75 & 6.307 & 3.851 & 3.762 & 4.384 & 12.272 & 1.244 \\
\hline & t-stat. & *** 4.846 & $* * 2.543$ & 1.938 & 1.664 & * 2.032 & $* * * 4.060$ & $* * * 5.509$ \\
\hline \multirow[t]{2}{*}{ Lin.Trend } & Coeff. & -0.53 & -0.024 & -0.018 & -0.026 & -0.005 & -0.072 & 0.027 \\
\hline & t-stat. & $* * *-2.974$ & -0.566 & -0.536 & -0.66 & -1.26 & -1.403 & $* * * 7.045$ \\
\hline
\end{tabular}

Table 2: Tests for the stylized facts that growth rates of world primary production and world GDP are equal to zero and trendless. The table presents coefficients and $t$-statistics for regressions of the growth rates on a constant and a linear trend. ${ }^{* * *},{ }^{* *}$, and ${ }^{*}$ indicate significance at the $1 \%, 2.5 \%$ and $5 \%$ level, respectively.

Sources: Schmitz $(1979)$, Neumann (1904), Metallgesellschaft (1904), Federal Institute for Geosciences and Natural Resources (2011c) and Maddison (2010) 


\begin{tabular}{|c|c|c|c|c|c|c|c|c|}
\hline & & Aluminum & Copper & Lead & Tin & Zinc & Crude Oil & World GDP \\
\hline Range & & 1855-2009 & 1821-2009 & $1802-2009$ & 1792-2009 & 1821-2009 & $1861-2009$ & 1792-2009 \\
\hline \multirow[t]{2}{*}{ Constant } & Coeff. & 48.301 & 5.474 & 20.57 & 4.427 & 30.7 & 35.689 & 0.032 \\
\hline & t-stat. & $* * * 3.824$ & $* * * 3.06$ & $* * * 3.845$ & * 2.181 & $* * 2.584$ & $* * * 4.379$ & 0.276 \\
\hline \multirow[t]{2}{*}{ Lin.Trend } & Coeff. & -0.229 & -0.018 & -0.125 & -0.023 & -0.182 & -0.19 & 0.01 \\
\hline & t-stat. & $* * *-2.677$ & -1.367 & $* * *-3.025$ & -1.457 & $*-2.071$ & $* * *-3.499$ & *** 11.066 \\
\hline Range & & 1855-2009 & $1850-2009$ & $1850-2009$ & 1850-2009 & 1850-2009 & 1861-2009 & 1850-2009 \\
\hline \multirow[t]{2}{*}{ Constant } & Coeff. & 48.301 & 5.399 & 5.629 & 3.179 & 5.18 & 24.681 & 0.628 \\
\hline & t-stat. & *** 3.824 & $* * * 3.254$ & ***3.169 & 1.961 & *** 3.541 & *** 4.733 & $* * * 4.052$ \\
\hline \multirow[t]{2}{*}{ Lin.Trend } & Coeff. & -0.229 & -0.027 & -0.047 & -0.024 & -0.03 & -0.19 & 0.01 \\
\hline & t-stat. & $* * *-2.677$ & -1.523 & $* *-2.442$ & -1.348 & -1.895 & $* * *-3.499$ & $* * * 5.876$ \\
\hline Range & & 1900-2009 & 1900-2009 & 1900-2009 & 1900-2009 & 1900-2009 & 1900-2009 & 1900-2009 \\
\hline \multirow[t]{2}{*}{ Constant } & Coeff. & 18.595 & 4.985 & 2.028 & 1.903 & 3.473 & 8.869 & 1.071 \\
\hline & t-stat. & $* * * 5.242$ & $* 2.241$ & 1.41 & 0.918 & 1.763 & $* * * 6.306$ & $* * * 4.862$ \\
\hline \multirow[t]{2}{*}{ Trend } & Coeff. & -0.184 & -0.042 & -0.027 & -0.023 & -0.026 & -0.09 & 0.01 \\
\hline & t-stat. & $* * *-3.315$ & -1.214 & -1.186 & -0.694 & -0.404 & $* * *-4.084$ & $* * * 3.01$ \\
\hline Range & & 1950-2009 & 1950-2009 & 1950-2009 & 1950-2009 & 1950-2009 & 1950-2009 & 1950-2009 \\
\hline \multirow[t]{2}{*}{ Constant } & Coeff. & 8.583 & 2.952 & 1.141 & -1.954 & 3.578 & 7.716 & 2.632 \\
\hline & t-stat. & *** 5.742 & *** 2.892 & 1.04 & 1.086 & $* * * 2.87$ & *** 7.493 & $* * * 7.444$ \\
\hline \multirow[t]{2}{*}{ Lin.Trend } & Coeff. & -0.156 & -0.044 & -0.35 & 0.051 & -0.065 & -0.18 & -0.016 \\
\hline & t-stat. & $* * *-3.667$ & -1.515 & -1.129 & 0.997 & -1.819 & *** -6.14 & -1.551 \\
\hline Range & & $1875-1975$ & $1875-1975$ & $1875-1975$ & $1875-1975$ & $1875-1975$ & $1875-1975$ & $1875-1975$ \\
\hline \multirow[t]{2}{*}{ Constant } & Coeff. & 50.004 & 5.854 & 3.413 & 3.317 & 3.942 & 11.789 & 0.834 \\
\hline & t-stat. & *** 4.81 & $* * 2.386$ & 1.738 & 1.480 & 1.851 & *** 3.933 & $* * * 4.509$ \\
\hline \multirow{2}{*}{ Lin.Trend } & Coeff. & -0.542 & -0.038 & -0.032 & -0.039 & -0.019 & -0.086 & 0.013 \\
\hline & t-stat. & $* * *-3.06$ & -0.908 & -0.959 & -1.028 & -0.517 & -1.691 & $* * * 4.004$ \\
\hline
\end{tabular}

Table 3: Tests for the stylized fact that growth rates of world per capita primary production and world per capita GDP are equal to zero and trendless. The table presents coefficients and $t$-statistics for regressions of the growth rates on a constant and a linear trend. ${ }^{* *},{ }^{* *}$, and $*$ indicate significance at the $1 \%, 2.5 \%$ and $5 \%$ level, respectively.

Sources: Schmitz $(1979)$, Neumann (1904), Metallgesellschaft (1904), Federal Institute for Geosciences and Natural Resources (2011c) and Maddison (2010). 


\begin{tabular}{|c|c|c|c|}
\hline & $\begin{array}{r}\text { Reserves/ } \\
\text { Annual production } \\
\text { (Years) }\end{array}$ & $\begin{array}{r}\text { Resources/ } \\
\text { Annual production } \\
\text { (Years) }\end{array}$ & $\begin{array}{r}\text { Crustal mass/ } \\
\text { Annual production } \\
\text { (Years) }\end{array}$ \\
\hline Aluminium & $139^{1 a}$ & $263,000^{1 a}$ & $48,800,000,000^{b c}$ \\
\hline Copper & $43^{a}$ & $189^{a}$ & $95,000,000^{a b}$ \\
\hline Iron & $78^{a}$ & $223^{a}$ & $1,350,000,000^{a b}$ \\
\hline Lead & $21^{a}$ & $362^{a}$ & $70.000 .000^{a b}$ \\
\hline Tin & $17^{a}$ & "Sufficient"a & $144.000^{a b}$ \\
\hline Zinc & $21^{a}$ & $158^{a}$ & $187.500 .000^{a b}$ \\
\hline Gold & $20^{d}$ & $13^{d}$ & $27,160,000^{e f}$ \\
\hline Rare earth ${ }^{2}$ & $827^{a}$ & "Very large"a & n.a. \\
\hline $\mathrm{Coal}^{3}$ & $129^{g}$ & $2,900^{g}$ & \\
\hline $\mathrm{Oil}^{4}$ & $55^{g}$ & $76^{g}$ & $1,400,000^{6 i}$ \\
\hline $\operatorname{Gas}^{5}$ & $59^{g}$ & $410^{g}$ & \\
\hline
\end{tabular}

Table 4: Availability of selected minerals in years of production left in the reserve, resource and crustal mass at the current mine production rate.

Reserves include all material which can currently be extracted. The definition of resources can be found in section 2.2 Sources: ${ }^{d}$ U.S. Geological Survey (2012), ${ }^{b}$ Perman et al. (2003), ${ }^{\text {U.S. Geological Survey (2011a), }{ }^{d} \text { U.S. Geological Survey }}$ (2011b),$e$ Nordhaus (1974), ${ }^{f}$ U.S. Geological Survey (2010), ${ }^{9}$ Federal Institute for Geosciences and Natural Resources (2011a) ${ }^{g}$ Littke and Welte (1992). Notes: ${ }^{1}$ data for bauxite, ${ }^{2}$ rare earth oxide, ${ }^{3}$ includes lignite and hard coal, ${ }^{4}$ includes conventional and unconventional oil, ${ }^{5}$ includes conventional and unconventional gas, ${ }^{6}$ all organic carbon in the earth's crust.

\section{Proofs}

\section{Proof of Proposition 1}

The amount of the resource obtained per unit of technology investment $A(M)$ is given by

$$
\begin{aligned}
A(M) & =D\left(h_{M}\right) \\
& =-\delta_{1} \ln \left(\delta_{2} \gamma_{1} e^{-\gamma_{2} M}\right) \\
& =-\delta_{1} \ln \left(\delta_{2} \gamma_{1}\right)+\delta_{1} \gamma_{2} M .
\end{aligned}
$$

Thus the marginal amount of the resource made available for one unit of technology investment $M$ is

$$
\frac{\partial A(M)}{\partial M}=\delta_{1} \gamma_{2}
$$

and thus a constant. The cost for a unit of the resource in terms of technology investment is constant as well and given by the amount invested per unit of the resource:

$$
F=\frac{1}{\delta_{1} \gamma_{2}} .
$$

\section{Proof of Proposition 2}

The model contains the dynamics of the three state variables capital $K$, intermediate good 
quality $B$ and the stock of the resources $X$ :

$$
\begin{aligned}
\dot{K} & =K^{\alpha} B^{1-\alpha}(1-n)^{\beta} R^{\nu}-C-E R-F S, \\
\dot{B} & =\eta \sigma B n, \\
\dot{X} & =S-R
\end{aligned}
$$

as well as two non-negativity constraints (the resource input $R$ is obviously positive since it is an essential input to production):

$$
\begin{aligned}
& S \geq 0 \\
& X \geq 0 .
\end{aligned}
$$

The Hamiltonian to be maximized is thus

$$
H=u(C)+\lambda\left[K^{\alpha} B^{1-\alpha}(1-n)^{\beta} R^{\nu}-C-E R-F S\right]+\mu[\eta \sigma B n]+\varphi[S-R]+w_{1} S+w_{2} X .
$$

The first order conditions for $S, K$ and $X$ are

$$
\begin{aligned}
-\lambda F+\varphi+w_{1} & =0, \\
\dot{\lambda} & =\delta \lambda-\lambda \alpha \frac{Y}{K}, \\
\dot{\mu} & =\delta \mu+w_{2} .
\end{aligned}
$$

Writing the last two of these in terms of growth rates yields

$$
\begin{aligned}
-\lambda F+\varphi+w_{1} & =0, \\
g_{\lambda} & =\delta-\alpha \frac{Y}{K}, \\
g_{\mu} & =\delta+\frac{w_{2}}{\mu} .
\end{aligned}
$$

The non-negativity conditions are

$$
\begin{aligned}
& w_{1} \geq 0, \quad w_{1} S=0, \\
& w_{2} \geq 0, \quad w_{2} X=0 .
\end{aligned}
$$


Let us first consider the case where there is a positive initial stock $X>0$. Then by condition (27) we have $w_{2}=0$. In that case and if $w_{1}=0$, then by (23) we have $g_{\lambda}=g_{\varphi}$ so that conditions (24) and 25) imply $\frac{Y}{K}=0$, which cannot be true in equilibrium. Therefore we have $w_{1}>0$ and it follows from equation (26) that $S=0$.

Now let us assume that the stock of the resource is zero, $X=0$. Then it is also constant over time, so that $\dot{X}=0$. From this it follows by $(9)$ that $S=R$.

\section{Proof of Proposition 3}

Using Proposition 2, the Hamiltonian to be maximized can be simplified to

$$
H=u(C)+\lambda\left[K^{\alpha} B^{1-\alpha}(1-n)^{\beta} R^{\nu}-C-(E+F) R\right]+\mu \eta \sigma B n .
$$

First order conditions are

$$
\begin{aligned}
\frac{\partial H}{\partial C}=u^{\prime}(C)-\lambda & =0, \\
\frac{\partial H}{\partial n}=\lambda \beta(1-n)^{\beta-1}(-1) K^{\alpha} B^{1-\alpha} R^{\nu}+\mu \eta \sigma B & =0, \\
\frac{\partial H}{\partial R}=\lambda(1-n)^{\beta} K^{\alpha} B^{1-\alpha} \nu R^{\nu-1}-\lambda(E+F) & =0, \\
\frac{\partial H}{\partial K}=\lambda(1-n)^{\beta} \alpha K^{\alpha-1} B^{1-\alpha} R^{\nu} & =\lambda \rho-\dot{\lambda}, \\
\frac{\partial H}{\partial B}=\lambda(1-n)^{\beta}(1-\alpha) K^{\alpha} B^{-\alpha} R^{\nu}+\mu \eta \sigma n & =\mu \rho-\dot{\mu} .
\end{aligned}
$$

The FOC with respect to $C$ can be written $C^{-\varepsilon}=\lambda$ and thus

$$
g_{\lambda}=-\varepsilon g_{K}
$$

The FOC with respect to $n$ can be written as $\mu=\beta c^{-\varepsilon} V(1-n)^{-1}[\eta \sigma B]^{-1}$ and thus

$$
g_{\mu}=(1-\varepsilon) g_{K}-g_{B}
$$

where we have used $g_{K}=g_{Y}=g_{C}$, see Barro and Sala-i-Martin (2004), chapter 2.5. The FOC with respect to $R$ can be written $\nu \frac{Y}{R}=E+F$ and thus

$$
g_{R}=g_{Y}=g_{K} .
$$


The FOC with respect to $K$ can be written as $\alpha c^{-\varepsilon} \frac{Y}{K}=c^{-\varepsilon} \rho+\varepsilon c^{-\varepsilon-1} \dot{c}$ and thus

$$
g_{K}=\frac{1}{\varepsilon}\left(\alpha \frac{Y}{K}-\rho\right)
$$

The FOC with respect to $B$ can be written as $\frac{1}{\mu} c^{-\varepsilon}(1-\alpha) \frac{Y}{B}+\eta \sigma n=\rho-\frac{\dot{\mu}}{\mu}$ and thus

$$
g_{B}=(1-\varepsilon)\left(1-\frac{\nu}{1-\alpha}\right) g_{K}+\eta \sigma-\rho+\frac{\nu \rho}{1-\alpha} .
$$

where we substituted in equation $(29)$.

From the production function we get

$$
g_{B}=\left(1-\frac{\nu}{1-\alpha}\right) g_{K}
$$

Substituting equation (31) into equation (33) we get

$$
g_{B}=\left(1-\frac{\nu}{1-\alpha}\right) \frac{1}{\varepsilon}\left(\alpha \frac{Y}{K}-\rho\right)
$$

Substituting equation (31) into equation (32) we get

$$
g_{B}=\frac{1-\varepsilon}{\varepsilon} \alpha \frac{Y}{K}-\frac{\rho}{\varepsilon}-\frac{1-\varepsilon}{\varepsilon} \alpha \frac{\nu}{1-\alpha} \frac{Y}{K}+\frac{\nu}{1-\alpha} \frac{1}{\varepsilon} \rho+\nu \sigma .
$$

Equating equation (34) and equation (35) yields

$$
\alpha \frac{Y}{K}=\eta \sigma \frac{1-\alpha}{1-\alpha-\nu} .
$$

Substituting this into equation (31) yields

$$
g_{K}=\frac{1}{\varepsilon}\left(\eta \sigma \frac{1-\alpha}{1-\alpha-\nu}-\rho\right) .
$$

\section{Proof of Proposition 4}

The FOC for the resource $R$ in the proof of Proposition 3 can be written as

$$
R=\frac{\nu Y}{E+F}
$$

Since output $Y$ grows exponentially and the other terms on the right are constant, $R$ grows 
exponentially as well.

Proof of Proposition 5

For the first statement use $F=\frac{1}{\delta_{1} \gamma_{2}}$ and Proposition 4. The second statement follows from Proposition 3. 